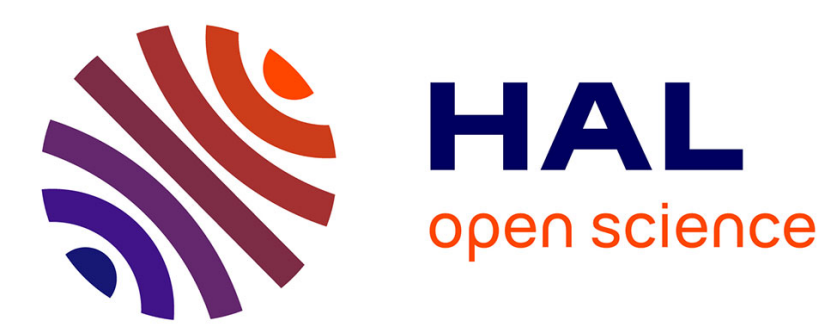

\title{
Magnetic pulse deformation of tubes made of partially polymerised carbon fibre reinforced plastic
}

\author{
V. Glouschenkov, B. Scheglov, Yu Moskalyov
}

\section{To cite this version:}

V. Glouschenkov, B. Scheglov, Yu Moskalyov. Magnetic pulse deformation of tubes made of partially polymerised carbon fibre reinforced plastic. Journal de Physique IV Proceedings, 1994, 04 (C8), pp.C8-343-C8-348. 10.1051/jp4:1994852 . jpa-00253412

\section{HAL Id: jpa-00253412 https://hal.science/jpa-00253412}

Submitted on 1 Jan 1994

HAL is a multi-disciplinary open access archive for the deposit and dissemination of scientific research documents, whether they are published or not. The documents may come from teaching and research institutions in France or abroad, or from public or private research centers.
L'archive ouverte pluridisciplinaire HAL, est destinée au dépôt et à la diffusion de documents scientifiques de niveau recherche, publiés ou non, émanant des établissements d'enseignement et de recherche français ou étrangers, des laboratoires publics ou privés. 


\title{
Magnetic pulse deformation of tubes made of partially polymerised carbon fibre reinforced plastic
}

V. Glouschenkov, B. Scheglov and Yu Moskalyov

Samara State Aerospace University, 34 Moskovskoye Shosse, Samara 443086, Russia

\begin{abstract}
The paper describes impulse deformation of tubes made of partially polymerized carbon filled plastic in combination with aluminium rings. A mathematical model is proposed for investigation of two stages of joint deformation. The first stage involves impulse deformation of an aluminium ring combined with carbon filled plastic mass. During the second stage the kinematics obtained at the first stage is used to determine the stress-strain state of a carbon filled plastic tube by the finite-element method. Changes in the stress-strain state due to a number of technological parameters are also described.
\end{abstract}

\section{INTRODUCTION}

One of the trends in the modern development of the machine-building industry is the application of composite materials of which unidirectional carbon filled plastics are the most actively used. For example, carbon filled plastic tubes are used for manufacturing ties, frameworks and trusses for aerospace vehicles, cardan shafts for the automobile industry, links for orthopaedic prosthetic appliances in the field of medicine and ski poles, etc. for the sporting industry.

One of the problems arising in manufacturing these structures is that of joining carbon filled plastic tubes and metal end pieces. Adhesive joints are not sufficiently reliable and cannot be adapted to stream-lined production. Bolted and rivetted joints are too complicated because they require holes and also entail an increase in weight.

In this paper a magnetic-pulse assembly technique is suggested. This involves producing the joint by radial deformation of a partially polymerized carbon filled plastic tube onto the metallic end piece. The deformation is produced by the radial contraction of an aluminium alloy ring which surrounds the composite tube and the end piece (or tip element), as shown in fig. 1. 


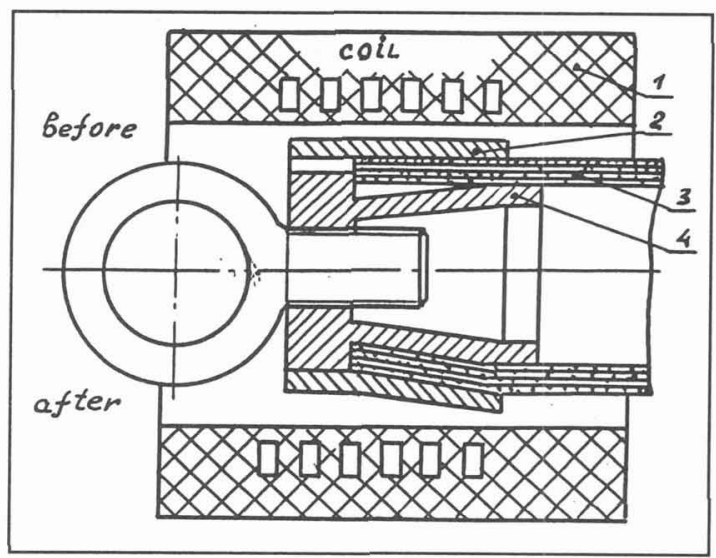

Fig. 1 Example of joint design and diagram of its realization by the magnetic-pulse technique.

(1 - coil; 2 - aluminium alloy ring; 3 -carbon filled plastic tube; 4 - tip element)

Tubes made of partially polymerized materials are sufficiently stiff to undergo all preparatory operations, e.g. transportation, cutting, grinding, etc., without damage. If the end of the tube is heated prior to the deformation process the state of the tube material becomes viscoelastic and the tube, therefore, may be shaped as is required. The final shape is determined by the length of the ring. After the joint has been made the polymerization process is completed, imparting the necessary structural strength and stiffness to the tube.

Two problems need to be solved if a high quality joint assembly of maximum structural strength is to be obtained. The first is to determine the effect of partial polymerization on the rheological properties of carbon filled plastic and hence on the degree to which the material may be deformed without destruction when the material is reheated. This problem was discussed in our paper to Explomet 90 [1] where information was given on the techniques used and some results were presented of our analysis of the mechanical properties of partially polymerized carbon filled plastics.

The second problem is the need for an analysis of the state of stress and strain in the carbon filled plastic material under the high rate deformation imposed during the joining process. This is likely to depend on a number or parameters, e.g. the geometrical dimensions of the components involved and the visco-elastic properties of the partially polymerised carbon filled plastic. However, the solution of this problem should lead to an understanding of the mechanisms of deformation of the composite tubes and the likely causes of their failure and so will help in determining the best possible assembly conditions.

\section{NUMERICAL ANALYSIS}

In order to solve this second problem a mathematical model has been devised which allows us to consider the deformation process in two stages. The first stage looks at the impulsive response of the aluminium ring combined with the mass of the carbon filled plastic tube and determines the kinematics of the process. The kinematics obtained in this way are then used in the second stage as boundary conditions for a finite element determination of the stress and strain state of the carbon filled plastic tube. Non-uniformity of material and anisotropy of its properties are taken into account.

\subsection{Analysis - Stage I}

In the analysis of the process of magnetic pulse reduction of a two-layered tube, as shown diagramatically in fig. 1 , it is assumed that the force and kinematic parameters depend primarily on the deformation resistance of the metal workpiece (i.e. the aluminium alloy ring), which is many times higher than that of the partially polymerized polymer binder. However, the inertia resistance due to the mass of the plastic binder is also considered. In these calculations the equivalent mass of a two-layered tube is used.

In the theoretical analysis of the first stage, relations are used which describe the axially symmetric 
forming of thin sheet metal. If the material is assumed to be incompressible, such that it gives an instantaneous plastic response, under conditions of either plane stress or plane strain, the set of equations for solving the above problem will take the form:

$$
\frac{\partial}{\partial S}\left(\sigma_{1} \delta_{x_{1}}\right)-\sigma_{2} \delta(1+e)=x_{1} \delta(1+e) \frac{\partial V_{i}}{\partial t} ; \quad p=\frac{\partial V_{2}}{\partial t}
$$

The various symbols in equations (1) are defined in fig. 2 which shows the loading on an infinitesimal element of the tubular workpiece.

Included in the set of equations is magnetic pressure, $\boldsymbol{P}$, which is defined by the formula:

$$
P=P_{M} \sin ^{2}(2 \pi t / T)
$$

where $\boldsymbol{P}_{\boldsymbol{m}}$ is the maximum amplitude of the magnetic field pressure and $T$ is the discharge current oscillation period. The

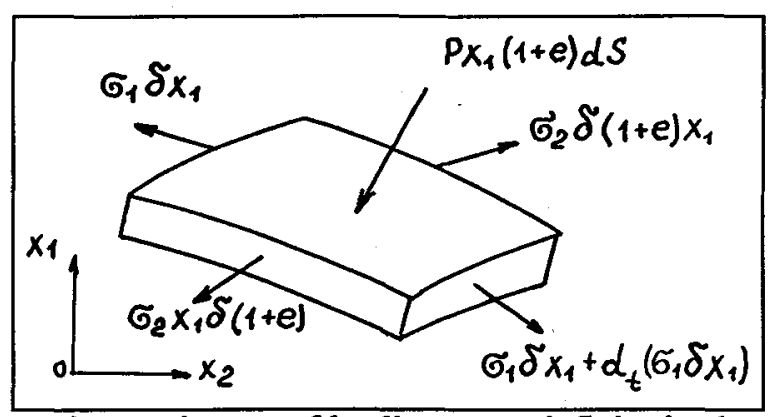

Fig. 2 Diagram of loading on an infinitesimal element magnetic pressure distribution along the generating line is described by the function:

$$
P_{2}(S)=4\left(S-S_{1}\right)\left(S_{2}-S\right) /\left(S_{1}-S_{2}\right)^{2}
$$

where $S_{1}, S_{2}$ are the boundaries of the loading region. Initial and boundary conditions for the tubular workpiece were assumed as follows:

- The tube is subjected to deformation under plane stress conditions when $\sigma_{3}=0$;

- When in contact with a mandrel (i.e. the tip element) meridional rates of deformation are absent, i.e. $\epsilon_{1}=0$;

- In a cross-section not subjected to deformation (i.e. when the tube is in contact with the tip element) it experiences a condition of rigid restraint given by $V_{1}=V_{2}=0$;

- $\quad$ On the free end face of the tube, even during deformation, $\sigma_{1}=0$.

For the above conditions a theoretical solution of the problem was performed using the numerical finite-difference method. The stress-strain state of material was determined as well as the distribution of rates and displacements.

\subsection{Analysis - Stage II}

The F.E. mesh used in the second stage of the analysis, i.e. for calculating the state of stress and strain in the tube during deformation, is shown in fig. 3 . The displacements, $U_{i}=\left(U_{i}\right)_{(t, S)}$, of the outer surface points of the carbon filled plastic tube used in this analysis were determined in the first stage. The carbon filled plastic composite of which the tube was made is modelled in the form of alternating cylindrical layers as shown in fig. 4, where layer 1 is unidirectional fibres impregnated with binder and layer 2 is unreinforced binder.

The binder layer is assumed to be isotropic. Anisotropy of the reinforced layers is due to the fibres which give the layer different mechanical properties in different directions. In our analysis it was assumed that the mechanical properties in the direction parallel to the reinforcing fibres were deter- 


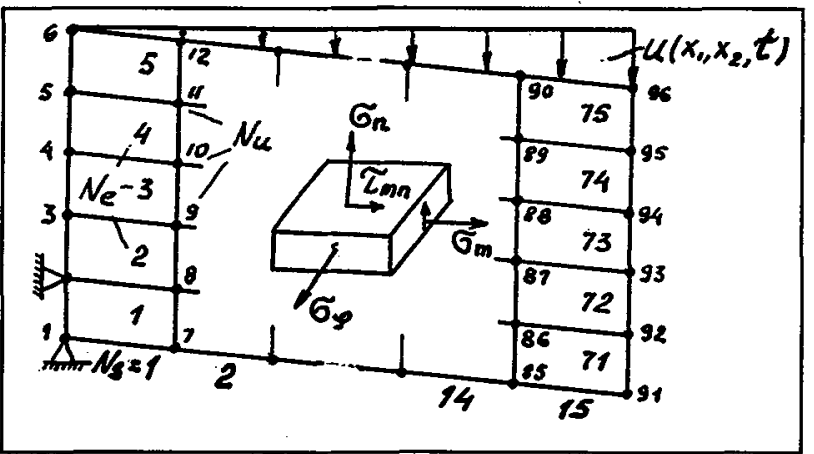

Fig. 3 Diagram of the second stage of the solution.

$\left(\mathbf{N}_{\mathrm{e}}\right.$ - element number; $\mathbf{N}_{\mathbf{u}}$ - node number; $\mathbf{N}_{\mathbf{s}}$ - axial layer number)

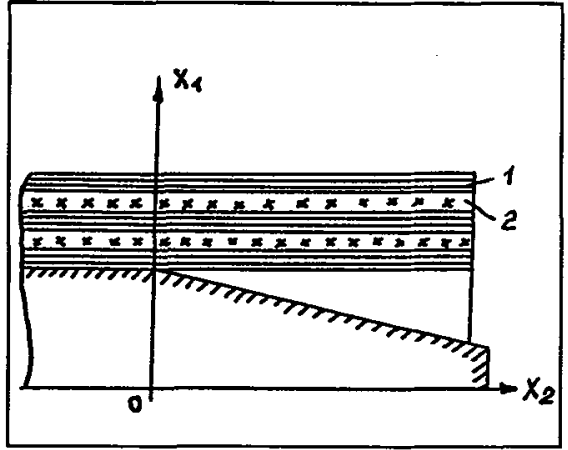

Fig. 4 Tube material model

$\left(1\right.$ - fibre in the binder layer $\left(E_{1}\right)$; 2 - binder layer $\left(\mathrm{E}_{2}\right)$ )

mined by those of the carbon fibres whereas in the direction perpendicular to the fibres the material was assumed to show the properties of a binder with a filling agent.

Experimental data show that the relationship $\sigma=f(\epsilon)$ is close to linear at deformation rates of the order expected for the magnetic-pulse reduction process. Accordingly, for the calculations described here an elastic anisotropic equation of state was used, of the form of a generalised Hooke's law for anisotropic materials. To solve the problem by the finite-element method the Hamilton variational principle is applied and the set of equations is solved by means of the Gaussian algorithm, see reference [2]. Displacements of nodal points of the material finite-element model are determined with subsequent recalculation in terms of stress and strain values in every finite element. Software implementation of solution algorithms is oriented to IBM-286 personal computers.

\section{RESULTS}

Calculations have been performed for a range of mechanical properties and boundary conditions including different magnetic pressures, different displacements imposed at the surface points of the tube, different numbers of layers and different limitations on the node displacements of elements of the cross-section restrained under cantilever bending. The numerical analysis is performed over a fixed period, up to the time at which the tangential deformation at the end of the tube, $\epsilon_{\boldsymbol{\psi}}$, approximately reaches $2 \%$.

The results of the analysis of the stress and strain state in a specific design model of carbon filled plastic tube are presented in fig. 5 . The variation of tangential shear stress, $\tau_{\mathrm{mn}}$, along a generator of the tube for an outer layer $a$ and an inner layer $b$ is compared in fig. 5a. Similarly fig. 5b compares the variation in the meridional (axial) stress, $\sigma_{m}$, along a generator for both layers $\mathbf{a}$ and $\mathbf{b}$, taking $E_{2}=500 \mathrm{MPa}$, and for the inner layer only, taking $\mathrm{E}_{2}=50 \mathrm{MPa}$. The different values for $\mathbf{E}_{2}$ relate to different degrees of partial polymerization. Fig. $5 \mathrm{c}$ shows compares the distribution of both the meridional, $\sigma_{m}$, and the normal, $\sigma_{n}$, stresses in the various layers from the outer (a) to the inner (b) for different elements along a generator, $N_{s}=1,5,10$ and 15.

\section{DISCUSSION}

The results obtained show that the distribution of stresses and strains along a generator of the tube is far from uniform. Thus, in fig. 5a, a very high shear stress, much higher than that elsewhere in the tube, is seen in the outer layer close to the constrained end, $O X_{1}$ in fig. 4 . Under certain 


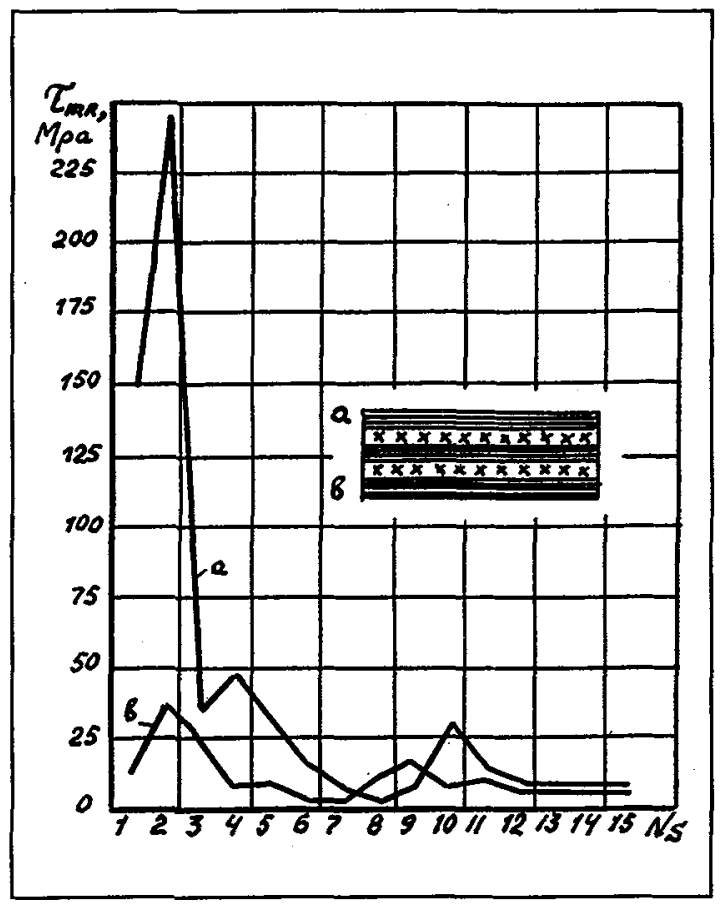

Fig. 5a Distribution of shear stresses along a generator in the outer (a) and inner (b) layers $\left(N_{s}=1\right.$ - close to constrained end; $\mathrm{N}_{\mathrm{s}}=15$ - close to free end)

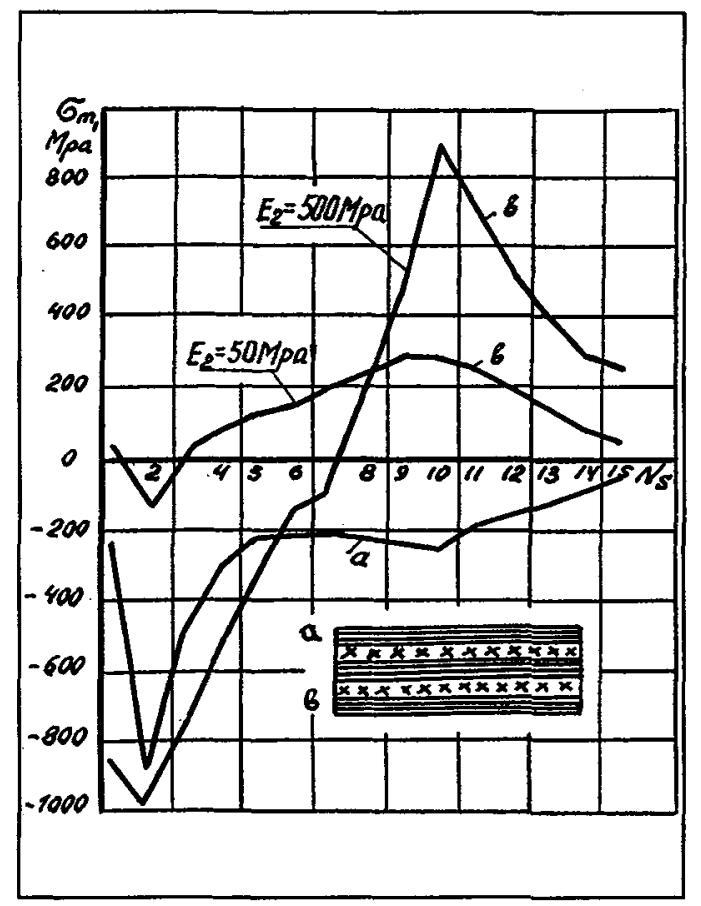

Fig. 5b Distribution of meridional stresses along a generator in both outer (a) and inner (b) layers for $\mathrm{E}_{2}=500 \mathrm{GPa}$ and in inner layer only for $E_{2}=50 \mathrm{MPa}$

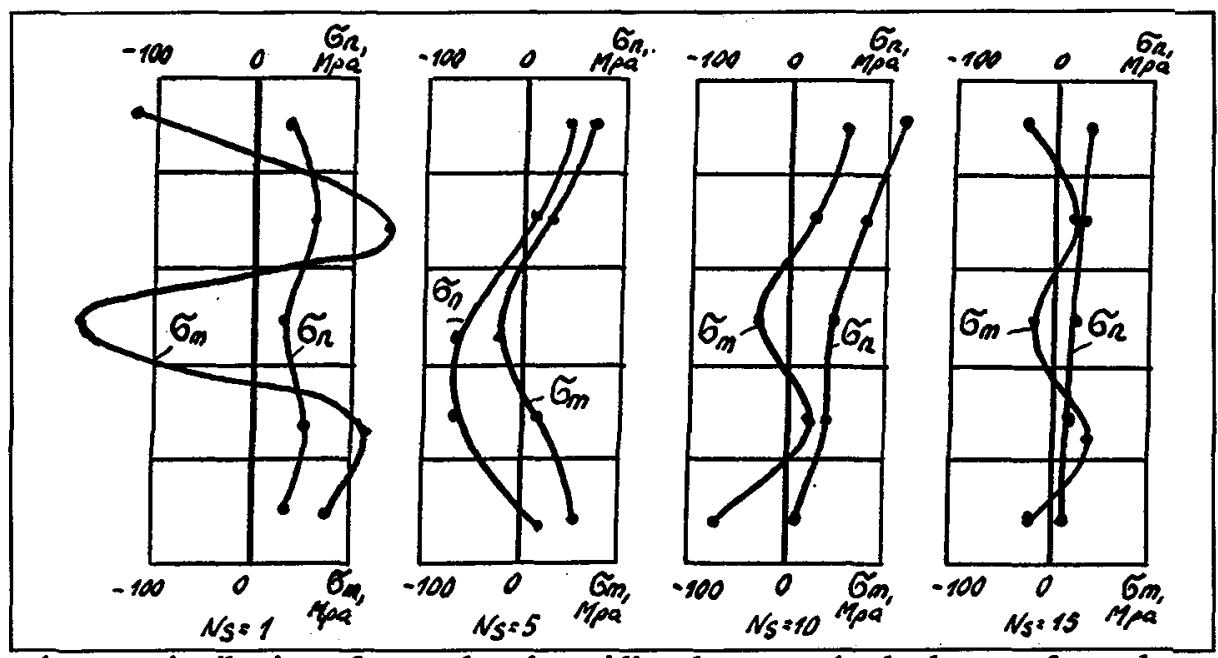

Fig. 5c Distribution of normal and meridional stresses in the layers of a carbonfilled plastic tube from the outer (a) to the inner (b) layers for different elements along a generator 
conditions, also, high values of tensile normal stress, $\sigma_{n}$, may be seen on the insided elements of the tube. Bonds between fibres and binder may be upset in regions of increased tangential shear stress if $\tau_{\mathrm{mn}}>[\tau]$ where $[\tau]$ is some critical value of this stress. Similarly bonds between fibres and matrix could be disturbed by high tensile normal stresses along the radial direction of the tube, see fig. 5c, leading to delamination. Alternatively breakage of fibres could occur as a result of high tensile meridional stresses, such as are seen in fig. $5 \mathrm{~b}$ in both the inner and the outer layers, close to the constrained end of the tube.

\section{CONCLUSIONS}

The proposed mathematical model allows a prediction to be made of the stress and strain state in carbon filled plastic tubes under various conditions of impulse loading and so provides some information on which the development of an optimised magnetic-pulse technique may be based.

\section{REFERENCES}

1. Glouschenkov, V.A., et al, Metallic elements and carboplastic pipes, Proc. Int. Conf. JOM-5, May 1991, Helsingor, Denmark

2. Новацкий В. Теория упругости. М. : Мир, 1975

3. Russell, L.T., Bowes, W.H., Stress Analyses by the Finite Element Method for Practising Engineers, Toronto, 1975. 